As one of the surgeons who introduced Dr Stradling to the art of bronchoscopy and who actually witnessed him achieve his first successful solo bronchoscopy, I am delighted to see this book run to a third edition in 8 years. Regrettably, with inflation, the price has now soared to $£ 15$ but at 10 pence an illustration it is still cheaper than photography and the pictures are such that they will never be surpassed or outdated. The book is now essential for all those who have to teach the art of bronchoscopy to new residents and it makes a useful and memorable leaving present for any worthwhile houseman or registrar.

One can forgive the occasional split infinitive-very often they prevent the text becoming too ponderous and 'bronchoscopically speaking' may well be a new form of speech, but why oh why must we continue to be subjected to oat-celled carcinoma and squamous-celled carcinoma when we mean oat cell and squamous carcinoma?

The publishers are to be congratulated on the excellence of their printing and reproduction of illustrations and it is hoped that on this occasion they will profit from their previous experience and print thousands of copies so that one will no longer be told that the edition is sold out within a few years of its becoming available.

\section{Diseases of the Thyroid}

By David Evered. Pp. 182, hard cover, illustrated. Tunbridge Wells: Pitman Medical, 1976. $£ 6.00$.

In recent years there has been a resurgence of interest in the physiology of the thyroid gland and this has led to improved laboratory techniques for the assessment of thyroid disorders. Diagnosis is more exact and new tests abound. The time is ripe for a book such as this to provide the physician with upto-date information on the workings and diseases of the thyroid gland. As befits a book by a single author, it is well balanced in material and style and the information presented is supported by good references to recent publications.

The chapter on hyperthyroidism would be easier to follow if Graves' disease were treated separately rather than as one aspect of hyperthyroidism, distracted by the interpositioning of nodular goitre, excess TSH syndrome and other comparative rarities. In critical vein, it is hard to understand why the electrocardiographic changes of hypothyroidism are not better discussed and few would agree that surgery for simple goitre is justified, in some patients, to allay anxiety.

These are minor blemishes in a book that ably serves its purpose of providing a clear description of the pathophysiological basis of thyroid diseases and a practical guide to their management. It is well produced, it is not too expensive and not too large and can be recommended to the general physician.

\section{Fractures and Joint Injuries, Volumes I and II}

By R. Watson-Jones. Edited by J. N. Wilson. Fifth edition. Pp. 1372, illustrated, hard cover. Edinburgh: Churchill Livingstone, 1976. $£ 45.00$.

Sir Reginald Watson-Jones was a remarkable man who, in his day, dominated the orthopaedic scene. His influence on fracture treatment was enormous and, despite his skill at lecturing, his pleasure in travelling and his personal dynamism, there can be no doubt that much of this influence came from his famous book. The four editions he himself produced were translated into numerous languages and scored critical superlatives on almost every count; the text was comprehensive, the advice was clear and practical, the production was lavish, and the language aglow with vitality.

It needed courage to attempt a fifth edition. Mr Wilson is a brave man; but he is not foolhardy and he wisely recruited a team of distinguished experts to help. His own contribution is far and away the biggest; he has revised and rewritten large sections and his views are always sound and safe. Each of the other contributors has dealt with a limited section, but because these are many, the result inevitably is uneven. A few chapters are notable (your reviewer particularly enjoyed Mr Colton's on Ankle Injuries, Professor Kessel's on The Shoulder and Mr Birnstingl's on Vascular Injuries), but some of the other contributors seem to have been overawed or overwhelmed by the shade of their predecessor.

The same aura makes it difficult for anyone familiar with the fourth edition to avoid comparing it with this one. Knowledge has certainly been updated, the quality of its communication equally certainly has not (indeed how could it be). The quality of production is a little lower, the price a great deal higher. And so on. Such comparisons, though inevitable, are invidious; the work must be assessed for its own qualities. It is, without doubt, an important and comprehensive account. Those who can afford $£ 45$ (not an unreasonable price for two large volumes) will enjoy it and will often refer to it. Above all $\mathrm{Mr}$ Wilson deserves to be congratulated on successfully completing a mammoth task.

\section{A Handbook of Treatment}

Edited by $\mathrm{H}$. W. Proctor and P. S. Byrne. Pp. $\mathrm{x}+434$, hard cover, illustrated. Lancaster: Medical and Technical Publishing Co Ltd, 1976. £9.95.

This is yet another multi-author book of medical treatment, which is designed, say its editors, to keep its readers abreast of developments in medicine that have an immediate effect on daily practice. In many respects they have achieved this goal, and its chapters on drugs in current use are generally up-todate, and include, for example, atenolol (Tenormin) and bromocriptine. Certain subjects, such as the treatment of neoplasia, wisely deal with general principles of management and discussion of recent advances, rather than giving treatment schedules which are properly the province of the expert oncologist. It is regretful, however, that the editors have not applied consistent editorial policies throughout the book. For example, the chapter on sexually transmitted diseases quotes references for its statements, but details of the sources are not given either at the end of the chapter or of the book. The success of such a book depends on its authoritativeness, based on the expertise of its contributors. It is a pity that some parts of this volume have been written more as an academic monograph than as an authoritative guide.

\section{Modern Trends in Psychosomatic Medicine-3}

The Modern Trends Series. Edited by Oscar W. Hill. Pp. 520, hard cover, illustrated. London: The Butterworth Group, 1976. £14.00.

This is the third edition of this volume. With each edition the Editor has drawn together a group of authoritative contributors able to make useful statements about the current status of the psychosomatic approach to a variety of diseases. The present volume is larger and more comprehensive than the previous ones and is almost uniformly good. It is difficult to do justice to twenty-four distinct chapters in a brief review but to quote the Editor in his introductory remarks: 'The refreshing modern trend in psychosomatics is to conceptualize the link between psychological factors and the intimate pathophysiological processes of the disease under study, rather than restricting the concept to a purely psychological formulation with a lofty disdain for the means whereby the psychological strain could be translated into physical changes'.

Early chapters are devoted to experimental work on animals and to psychophysiological (e.g. biofeedback) and psychoendocrinological aspects. Some of the remaining chapters are theoretical but the majority reflect sound clinical wisdom and experiment. Those on the measurement of 'life events', pain, asthma, hypertension, peptic ulcers, disorders of weight, the care of the dying and of the bereaved, stand out. 